\title{
Refeeding syndrome in the frail elderly population: prevention, diagnosis and management
}

This article was published in the following Dove Press journal:

Clinical and Experimental Gastroenterology

\section{Emilie Aubry' \\ Natalie Friedli ${ }^{2}$ \\ Philipp Schuetz ${ }^{2}$ \\ Zeno Stanga'}

'Department for Diabetes, Endocrinology, Nutritional Medicine and Metabolism, Bern University Hospital and University of Bern, Bern, Switzerland; ${ }^{2}$ Medical University Department, Clinic for Endocrinology, Diabetes, Metabolism and Clinical Nutrition, Kantonsspital Aarau, and Medical Faculty of the University of Basel, Basel, Switzerland
Correspondence: Zeno Stanga Department for Diabetes, Endocrinology, Nutritional Medicine and Metabolism, Bern University Hospital and University of Bern, 3010 Bern, Switzerland Tel +4I 3 I 6324246

Email zeno.stanga@insel.ch

\begin{abstract}
Aging is linked to physiological and pathophysiological changes. In this context, elderly patients often are frail, which strongly correlates with negative health outcomes and disability. Elderly patients are often malnourished, which again is an independent risk factor for both frailty and adverse clinical outcomes. Malnutrition and resulting frailty can be prevented by adequate nutritional interventions. Yet, use of nutritional therapy can also have negative consequences, including a potentially life-threatening metabolic alteration called refeeding syndrome (RFS) in high-risk patients. RFS is characterized by severe electrolyte shifts (mainly hypophosphatemia, hypomagnesemia and hypokalemia), vitamin deficiency (mainly thiamine), fluid overload and salt retention leading to organ dysfunction and cardiac arrhythmias. Although the awareness of malnutrition among elderly people is well established, the risk of RFS is often neglected, especially in the frail elderly population. This partly relates to the unspecific clinical presentation and laboratory changes in the geriatric population. The aim of this review is to summarize recently published recommendations for the management of RFS based on current evidence from clinical studies adapted with a focus on elderly patients.
\end{abstract}

Keywords: refeeding syndrome, frail, elderly, management, malnutrition

\section{Introduction}

Pathophysiological signs and symptoms, such as functional and mental decline, socioeconomic problems, loss of teeth and changes in the smell and taste senses, occur with older age. Some older people become frail over time. Frailty is a biological syndrome with multiple dimensions, which results from cumulative declines across multiple physiological systems and leads to worse outcomes (disability, poor quality of life) due to decreased reserves and low resistance to stressors. ${ }^{1}$ Frailty is affected by age, gender, lifestyle and socioeconomic status, as well as by comorbidities and cognitive and sensory impairments. ${ }^{2-4}$ However, frailty does not mean disability, which is characterized by physical and/or mental limits on activities and social participation; instead, it is a form of pre-disability., ${ }^{4,5}$ Frailty predicts negative clinical outcomes (falls, polypharmacy, hospital and nursing home admission) and is associated with a higher risk of mortality. ${ }^{6-9}$ The criteria for frailty syndrome have been defined by Fried et al: unintentional weight loss ( $>5 \%$ weight loss over 1 year), self-reported exhaustion, weakness, slow walking speed and low physical activity level. People who meet two of these criteria are pre-frail, and those who meet three or more criteria are frail. ${ }^{9}$

As frailty is a reversible process, it can be positively influenced by adequate nutritional support because of the close association between poor nutritional status 
and frailty syndrome in older adults. ${ }^{10-13}$ Micronutrient deficiencies and low protein intake which leads to sarcopenia (the weakening of skeletal muscle tissue and the subsequent functional decline with age) are related to frailty, thus increasing the risk of frailty syndrome. ${ }^{1,14}$ Nutritional intervention, together with resistance training, contributes to reducing frailty. ${ }^{15-18}$

Malnutrition is a main topic in the frail elderly population, as up to $50 \%$ of older people have a high risk for malnutrition. Malnutrition is highly prevalent in European hospitals (20-60\%) and is especially frequent in geriatric patients. It can thus be seen as the cause or the consequence of disease: malnutrition can worsen the course of the disease and be caused by the disease itself. ${ }^{19-24}$

Nutritional therapy aims to reduce the negative effects of malnutrition, such as higher morbidity, higher complication rates and thus longer hospital stays and mortality. The refeeding syndrome (RFS) is a potential life-threatening complication of the nutritional therapy in the replenishment phase. It is known and has been studied for over 70 years, beginning at the end of World War II with the death of many fasting prisoners after they started a normal diet again and also shown in Keys' Minnesota experiment with young healthy participants. ${ }^{25-27}$ From a pathophysiological point of view, RFS is an exaggerated response of the malnourished catabolic body to a nutritional therapy, indeed to anabolism. The intake of food, and therefore the switch from a catabolic to an anabolic metabolism, causes electrolyte and fluid disturbances, as well as limitations of organ functions. ${ }^{28,29}$ Symptoms such as heart failure, peripheral edema and neurologic disorders can occur. Protein, lipid and glucose metabolisms are disturbed, and a lack of vitamins, especially thiamine (vitamin B1), occurs. If not treated, these disturbances can lead to severe negative effects, from multiorgan dysfunction to death. ${ }^{28-32}$

To date, the awareness of malnutrition in the elderly population is well established, whereas the potential lifethreatening risk of RFS is much less known, especially in elderly patients. ${ }^{29,33,34}$ Screening for RFS risk is not commonly done. Even when malnutrition is present, the risk of RFS is usually neglected or overlooked among hospitalized or institutionalized patients. ${ }^{35}$

\section{Pathophysiology and clinical manifestations of RFS}

RFS, the exact pathophysiology of which remains unclear, mostly occurs within the first 72 hours after the start of nutritional therapy and shows a rapid progression. It emerges from the switch from a catabolic to an anabolic state after a prolonged starving period. During this fasting period, glucose oxidation is reduced. Insulin secretion is therefore decreased, and glucagon and catecholamine levels are increased. ${ }^{37}$ Glycogen reserves are consumed. ${ }^{36}$ Gluconeogenesis starts along with lipolysis and proteolysis to maintain energy production. As a result, muscle proteins are wasted, as well as vitamin and electrolyte stores. ${ }^{36,38}$ Through lipolysis, blood levels of free fatty acids increase, and ketogenesis in the liver is stimulated. ${ }^{38}$ Therefore, ketone bodies, mainly hydroxybutyrate, become the main energy suppliers of the organism (Figure 1).

By the start of the nutritional therapy, carbohydrates are the main energy suppliers, and concentration of glucose suddenly increases causing hyperglycemia. The insulin secretion subsequently increases and stimulates the anabolic processes. Intracellular shifts of glucose and electrolytes (phosphate, potassium, magnesium) occur, and their blood levels may drop severely. These drops can lead to life-threatening spasms or arrhythmia. ${ }^{28,30,36,39,40}$

As previously mentioned, the increased insulin secretion causes the intracellular uptake of phosphate. Phosphate is important for the intracellular metabolism of macronutrients for both energy production, as glucose must be phosphorylated to enter glycolysis, and energy transfer. Hypophosphatemia, the most common definitional criterion of RFS, can cause neuromuscular, neurologic, respiratory and/or hematologic problems. ${ }^{36,41}$ Hypokalemia and hypomagnesemia both can cause arrhythmia as well as rhabdomyolysis, paresis, confusion and respiratory insufficiency. ${ }^{36}$

Along with the increased insulin secretion in the early phase of refeeding, the kidneys tend to retain sodium, which induces water retention indeed. The consecutive rise of extracellular volume can lead to peripheral edema and heart failure.

Both electrolyte and vitamin deficiencies often arise, primarily due to a lack of thiamine. ${ }^{38}$ Thiamine is an important cofactor in the metabolism of carbohydrates, which allows for energy production. It enables the conversion from glucose to ATP (Krebs cycle). In cases of thiamine deficiency, glucose is converted to lactate by the lactate dehydrogenase, leading to metabolic acidosis. Thiamine deficiency thus may lead to neurologic (Wernicke's encephalopathy, dry beriberi) or cardiovascular disorders (wet beriberi), together with water retention. ${ }^{36}$

Briefly and according to the long clinical experience of the authors, the three main symptoms of RFS are tachycardia, tachypnea and edema, but there are many unspecific symptoms occurring in the manifestation of RFS..$^{28,36,42}$ 


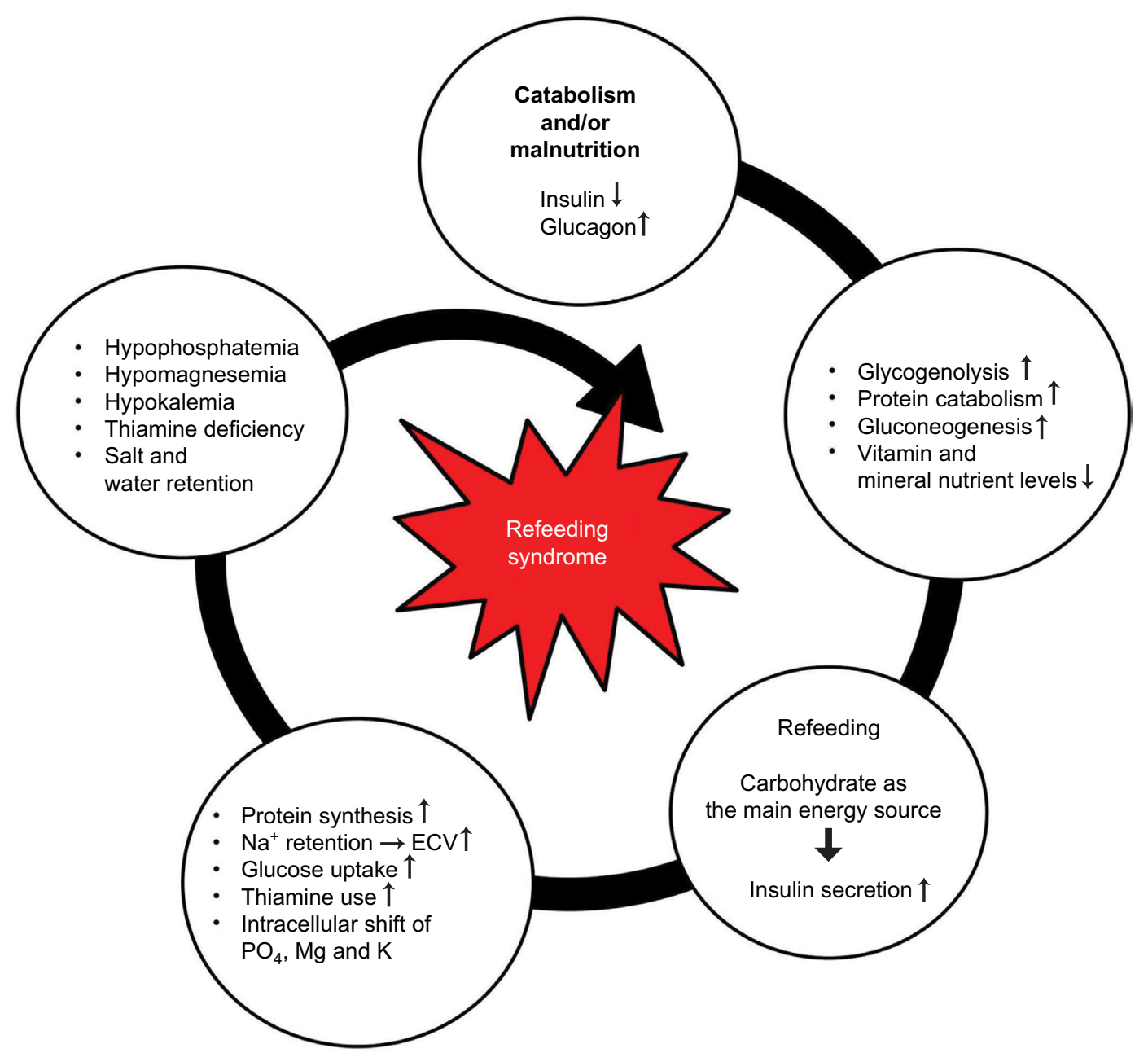

Figure I Pathophysiology of the RFS.

Note: Used with permission of the Department of Diabetes, Endocrinology, Nutritional Medicine and Metabolism and is modified from Stanga et al. ${ }^{29}$ Abbreviations: RFS, refeeding syndrome; ECV, extracellular volume.

\section{Current level of evidence on RFS}

The overall evidence level regarding RFS is poor, especially in the frail elderly patient population. Only few randomized controlled studies are available. A recent review of Friedli et al summarizes the best actual evidence on hand. ${ }^{42}$ Based on this review, there is an experts' consensus defining risk factors, timely occurrence and a possible algorithm for the prevention, diagnosis and treatment of RFS in medical inpatients. However, even though there has been awareness of RFS for over 70 years, there is no universally accepted definition for it, and there is a lack of strong evidence for incidence rates, prevention and therapy. ${ }^{34,43-46}$ Thus, many cases probably stay unrecognized and therefore untreated, especially in older hospitalized patients, as its clinical manifestations are nonspecific and similar to other symptoms in this population (eg, weakness, confusion and poor mobility).

The guidelines of the National Institute for Health and Care Excellence (NICE) are widely used for the nutritional medical support of adults. ${ }^{46}$ These guidelines give advice on the recognition of malnutrition through the management of nutritional therapy (oral, enteral or parenteral). The newly published experts' consensus statement based on the review on RFS of Friedli et al provides an algorithm for the management of patients with nutritional therapy in order to prevent and treat RFS. ${ }^{42}$

\section{Prevention}

\section{Nutritional support team}

As the early identification of at-risk patients and the recognition of RFS are crucial, well-trained medical staff are needed. Specialized nutritional support teams, consisting of physicians, dieticians, nurses and pharmacists, are present in many hospitals. These multidisciplinary nutritional support teams assist the attending medical staff in the management of patients receiving nutritional therapy to optimize the patients' outcome. 


\section{Risk factors and risk identification}

Possible predictors for RFS are analyzed in many studies, for example, low energy intake for over 10 days or weight loss over $15 \%$. Their sensitivity (67\%) and specificity (80\%) are low. ${ }^{47-49}$ Low serum magnesium $(<0.7 \mathrm{mmol} / \mathrm{L})$ was the only significant predictor in the study of Rio et al. ${ }^{50}$ Starvation itself is the most reliable predictor. ${ }^{50}$ In addition to oncologic patients, patients with eating disorders, patients with limited nutrient absorption (after bariatric surgery, with short bowel syndrome), patients with chronic vomiting or diarrhea and patients with chronic medication also have a higher risk of developing RFS. ${ }^{42,51-55}$

Older age, high Nutritional Risk Screening (NRS-2002) scores $(\geq 3)$ and comorbidities were found to be risk factors for RFS in many studies. ${ }^{35,56}$ The NICE guidelines even indicate that frail elderly people or older people living alone are more likely to be at risk for RFS. ${ }^{46}$

RFS incidence can be up to $48 \%$ in malnourished patients and $14 \%$ in the geriatric population. ${ }^{57,58}$ Pourhassan et al showed that almost $75 \%$ of hospitalized geriatric patients with a risk for malnutrition were also at risk for RFS. ${ }^{35}$ As malnutrition is the most predominant and frequent clinical condition in elderly patients, there is a high risk for RFS for this patient population. Pourhassan et al investigated the relationship between the risk for malnutrition and the risk for RFS in an elderly population with three common screening tools: the NRS-2002 in inpatients, the Malnutrition Universal Screening Tool (MUST) in outpatients and the Mini Nutritional Assessment (MNA) in older institutionalized patients. ${ }^{35,59-61}$ According to the NRS-2002, 74\% were at risk for malnutrition, and $75.9 \%$ thereof were at high risk for RFS. According to the MUST score, $49.7 \%$ were at risk for malnutrition, and $95.4 \%$ thereof were at risk for RFS (with MUST $\geq 3: 100 \%$ ). According to the MNA, 55.8\% were at risk for malnutrition, and $69.1 \%$ of these were at risk for RFS.

According to these results, across all screening methods, patients at risk for malnutrition and for RFS had significantly higher weight loss in the past 6 months and lower magnesium and potassium levels than the malnourished patients not at risk for RFS. There were no differences in age or body mass index. ${ }^{35}$ However, the high prevalence of malnutrition in the geriatric population may indicate that age is a confounder rather than an independent predictive factor of RFS risk. ${ }^{62}$

RFS can occur with all forms of artificial nutrition; however, it is more frequently observed in patients receiving enteral nutrition, due to the stimulation of GLP-1, followed by parenteral nutrition. RFS is associated with severe complications but can potentially be avoided. ${ }^{47,50,57}$ Risk stratification is therefore essential before the start of the nutritional therapy
(Figure 2), which should then be individually adapted according to the patient's risk for RFS. ${ }^{42,46}$ However, if older patients are at risk for malnutrition, there is no need to perform a risk stratification. They can be considered at risk for RFS, as both the risk of malnutrition and the risk of RFS overlap. ${ }^{35,56}$

\section{Diagnosis}

The definition of RFS is based on serum electrolyte disturbances, especially hypophosphatemia, and on clinical symptoms. ${ }^{63}$ Hypophosphatemia is common in elderly geriatric patients $(14 \%)$, if tested, and is related to the occurrence of RFS. ${ }^{35,58}$ It can be especially detrimental in frail elderly patients, particularly in those with several comorbidities. It is an independent predictor of mortality and causes a threefold increase in mortality: the more severe the hypophosphatemia, the worse the outcome..$^{58}$ Based on the algorithm of Friedli et al, the diagnosis of RFS is based on hypophosphatemia, defined as a decrease in phosphate values $>30 \%$ under the initial value or $<0.6 \mathrm{mmol} / \mathrm{L}$, or if two other electrolytes decrease under their normal values. ${ }^{42}$ The electrolyte disturbances may cause clinical symptoms, such as edema, respiratory insufficiency or heart insufficiency, together with fluid imbalance and micronutrient deficiencies. ${ }^{28,36}$ The critical timeframe for RFS is the first 72 hours. When electrolyte disturbances are present alone within 72 hours, it is considered an imminent RFS. In case of electrolyte disturbances associated with clinical symptoms within 72 hours, RFS is manifest (Figure 3).

\section{Management}

Generally, RFS is a rare complication; nevertheless, nutritional therapy should be adapted depending on the individual risk factors of every patient. Figure 4 shows the detailed recommendations for the nutritional management of all risk categories. $^{42}$

\section{Fluids}

Hydration status is a key point in the management of RFS. Thus, prevention and treatment of RFS also means fluid management. As Tsiompanou et al showed, even if the awareness for RFS is present and restrictions in energy input and rate are made, RFS can occur due to intravenous fluid shifts/ overload. ${ }^{64}$ Overhydration is an issue, especially in frail elderly patients. ${ }^{64}$ Older patients may suffer from dehydration and need fluid resuscitation, but they have an increased risk for overhydration due to comorbidities (eg, heart failure) and age-related decrease in organ function. ${ }^{64}$ Also, the choice of appropriate fluid is of special importance. Recent studies prefer balanced electrolyte solutions to $0.9 \% \mathrm{NaCl}$ solutions, 


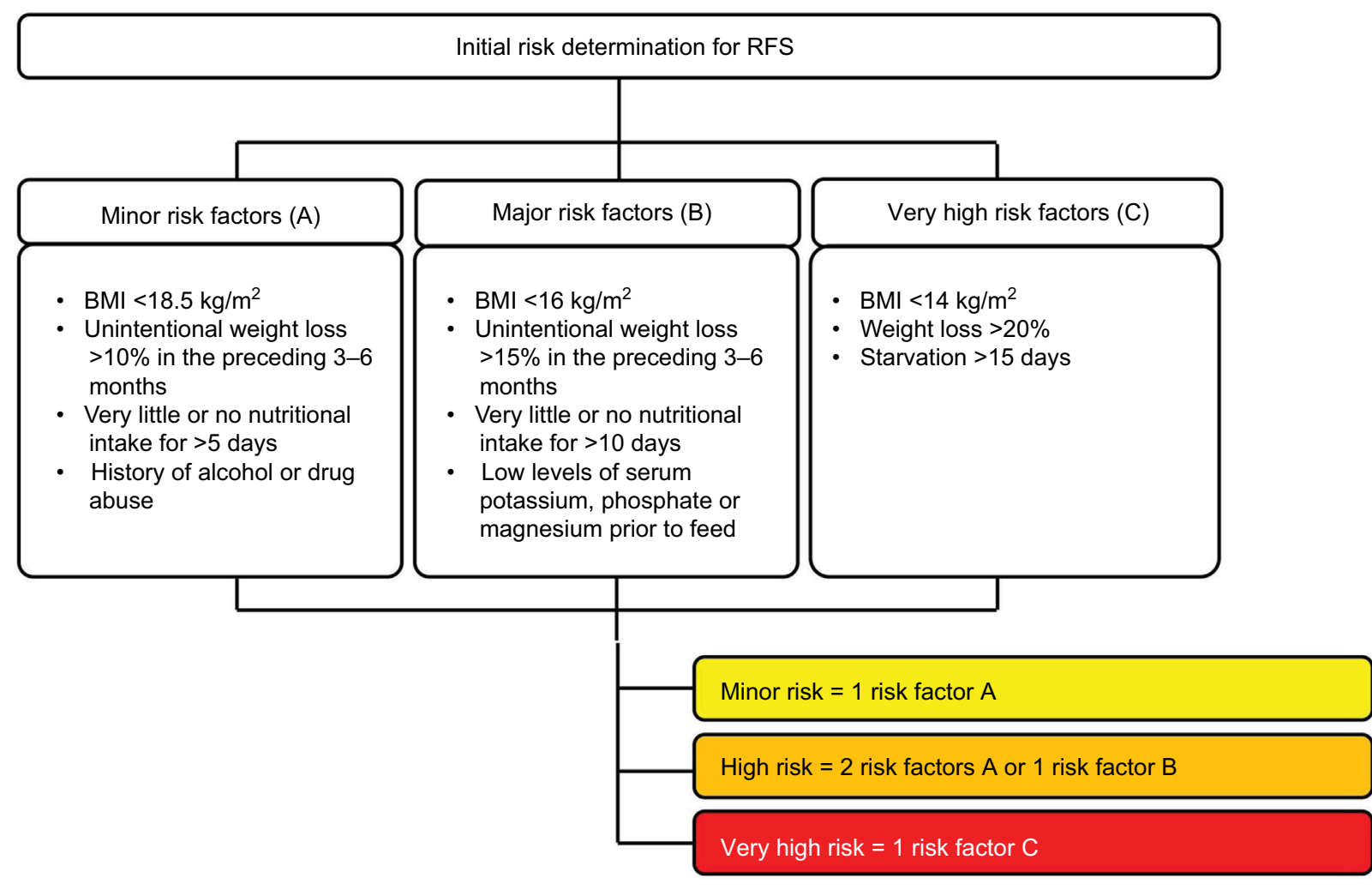

Figure 2 Identification of patients at risk for RFS.

Note: Used with permission of the Department of Diabetes, Endocrinology, Nutritional Medicine and Metabolism and is modified from Friedli et al ${ }^{42}$ and from National Institute for Health and Clinical Excellence (NICE). ${ }^{46}$

Abbreviations: RFS, refeeding syndrome; BMI, body mass index.

Decrease of $\mathrm{PO}_{4}$ from baseline $>30 \%$ or $<0.6 \mathrm{mmol} / \mathrm{L}$

or

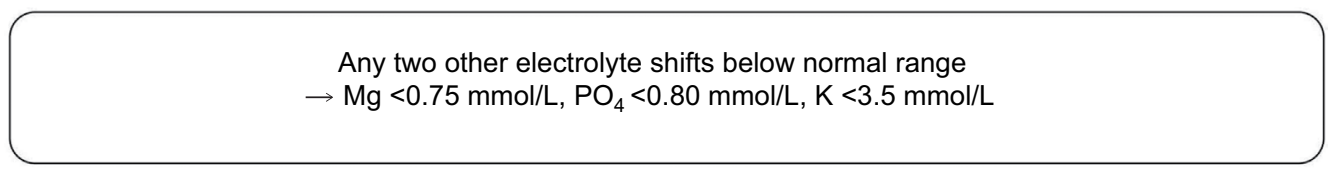

YES

Associated with clinical symptoms?

- Edema

- Tachycardia

- Tachypnea

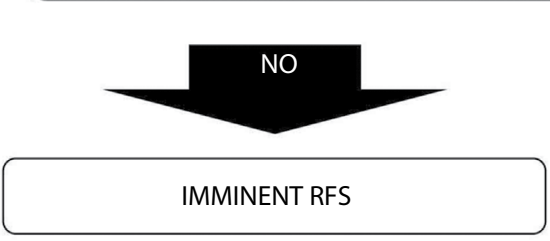

YES

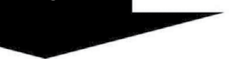

MANIFEST RFS

Figure 3 Diagnosis of RFS.

Note: Used with permission of the Department of Diabetes, Endocrinology, Nutritional Medicine and Metabolism and is modified from Friedli et al. ${ }^{42}$ Abbreviation: RFS, refeeding syndrome. 
A

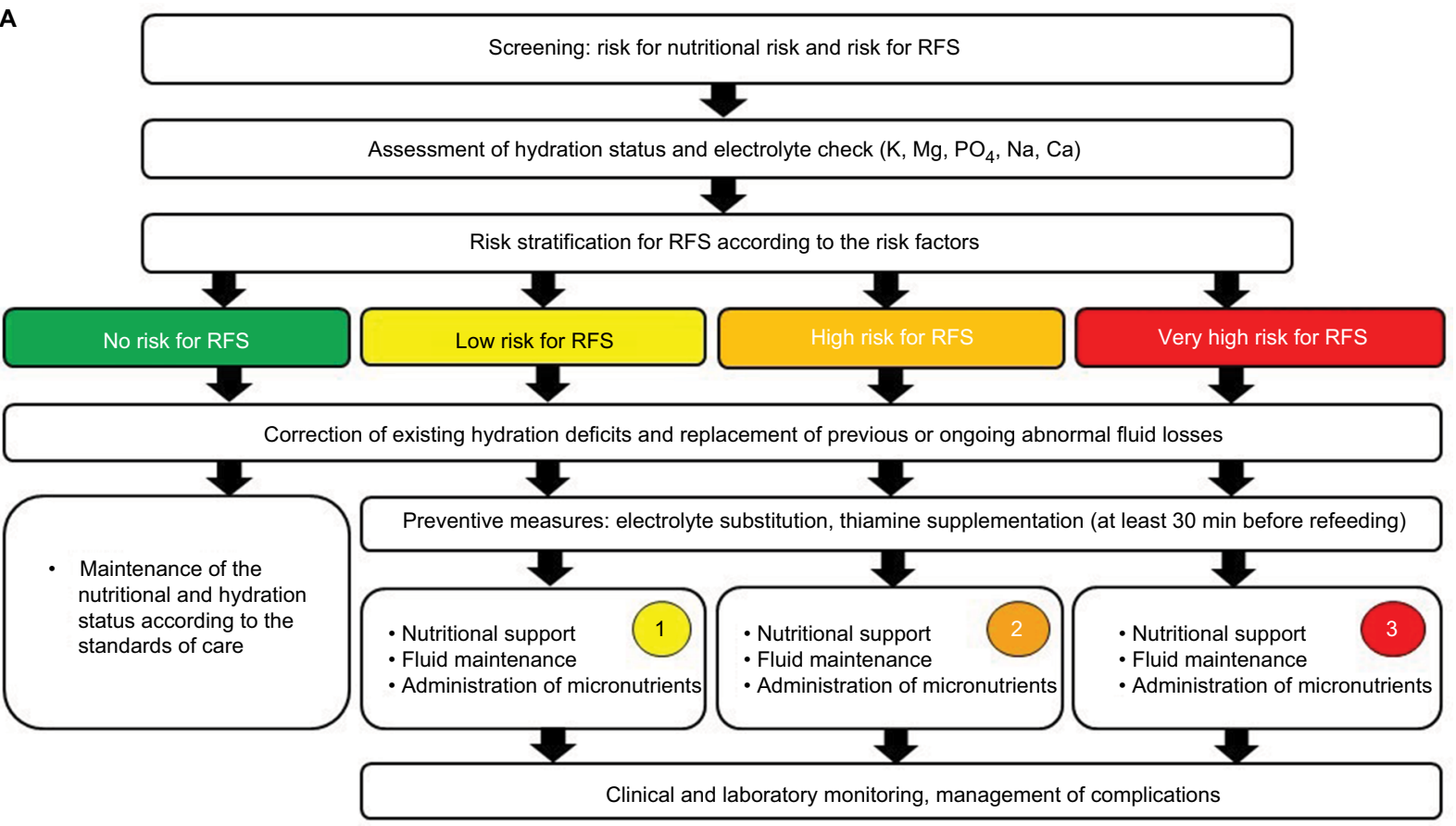

๑) UDEM
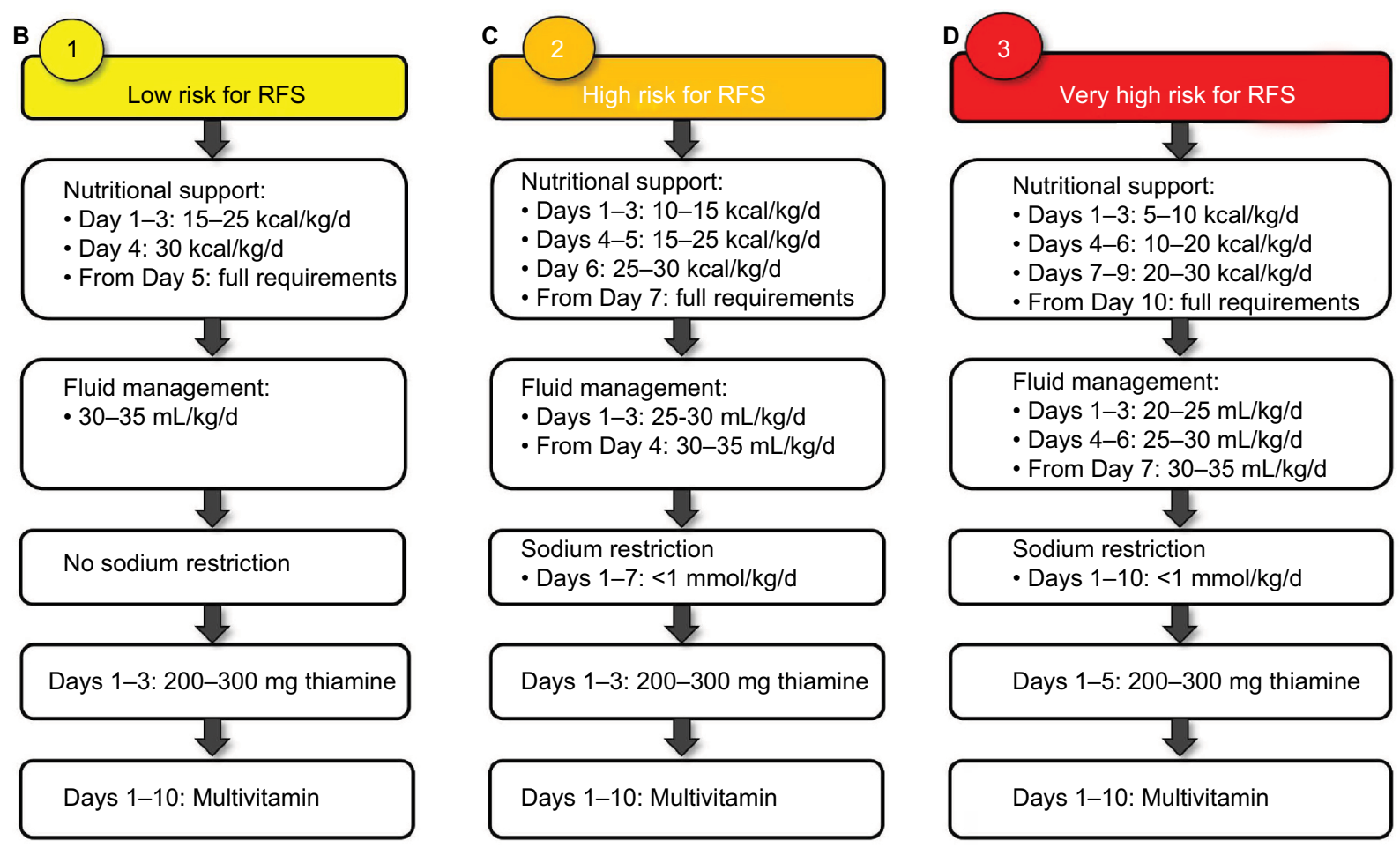

Figure 4 Management of nutritional therapy in patients at risk for RFS: (A) for patients of all risk categories; (B) for patients at low risk; (C) for patients at high risk; (D) for patients at very high risk.

Note: Used with permission of the Department of Diabetes, Endocrinology, Nutritional Medicine and Metabolism and is modified from Friedli et al. ${ }^{42}$

Abbreviation: RFS, refeeding syndrome. 
except in cases of fluid loss over a stoma or fistula. ${ }^{65}$ The sodium retention due to insulin secretion after the refeeding leads to extracellular volume expansion and vasoconstriction. ${ }^{66}$ Salt restrictions ( $\mathrm{Na}<1 \mathrm{mmol} / \mathrm{kg}$ body weight per day) are therefore needed in patients with (very) high risk for RFS to encounter this phenomenon. A fluid input of $20-25 \mathrm{~mL} / \mathrm{kg}$ body weight per day is generally needed to maintain the balance. In cases of fluid and/or salt restrictions, it is important to take into account the volume and the amount and salt content of the intravenous solution (up to $6 \mathrm{~g} / \mathrm{L}$ in Ringer's lactate solution or $9 \mathrm{~g}$ in $0.9 \% \mathrm{NaCl}$ solution) and the intravenously administered drugs, as well as parenteral nutrition. ${ }^{65}$

\section{Energy}

Most studies as well as the NICE guidelines recommend starting nutritional therapy with low caloric input and increasing step by step over 5-10 days, according to the individual's risk of RFS and clinical features. ${ }^{28,46,67-70}$ Given the small number of extant randomized studies, this approach shows the best evidence level available. ${ }^{43}$ It is recommended to start nutritional support with an amount of 5-15 kcal/ $\mathrm{kg}$ body weight per day (40-60\% carbohydrate, $30-40 \%$ fat and $15-20 \%$ protein), depending on the risk category.

\section{Micronutrients}

As mentioned, the refeeding of catabolic patients causes an intracellular shift of electrolytes and vitamins (mainly thiamine), the stores of which may be empty. Blood levels drop subsequently. Therefore, it is very important to replete electrolyte levels before the start of the nutritional therapy. This step is especially important for phosphate and thiamine. ${ }^{36,42}$ Supplementation should therefore be started in a preventive manner, even for normal phosphate levels. As fat oxidation does not require phosphate-containing products, phosphate stores of the body can be completely depleted while circulating levels are within the normal range. ${ }^{36}$ Frequent assessment of phosphate levels is thus mandatory before and during refeeding to avoid RFS or minimize its consequences, as hypophosphatemia plays a key role in RFS. ${ }^{29,36,71}$

Thiamine administration is essential as its body stores rapidly decrease. High-dose thiamine (200-300 mg) should be given 30 minutes before the start of the refeeding, at the latest. Other vitamins should be supplemented to $200 \%$ of the recommended daily intake (RDI), and trace elements should be supplemented to $100 \%$ of the RDI.

Other electrolytes, especially magnesium and potassium, should be supplemented according to blood levels. Magnesium is mandatory for the activity of the cellular sodium-potassium pump and is therefore important for the reabsorption of potassium. Therefore, hypomagnesemia should always be corrected when present with hypokalemia; otherwise, the hypokalemia cannot be corrected, and there is a potassium refractory state. ${ }^{72}$

In contrast, iron should not be supplemented within the first 7 days of nutritional support, as iron administration supports blood production, which increases potassium needs, and hypokalemia can be worsened. Further, parenteral iron substitution should be considered with caution in catabolic patients, as parenteral iron supplementation can induce and/ or prolong hypophosphatemia. ${ }^{73}$

If the electrolyte levels drop severely during the nutritional therapy (imminent RFS), they must be repleted adequately. In cases of manifest RFS, electrolyte repletion should be intensified, and nutritional therapy (energy and fluids) should be reduced, according to the highest risk category. Thus, clinical symptoms must be treated. Table 1 shows the possible repletion protocol.

Table I Suggested supplementation regimen $28,29,74-78$

\begin{tabular}{|c|c|c|c|}
\hline & Potassium & Magnesium & Phosphate \\
\hline Mild & $3.1-3.5 \mathrm{mmol} / \mathrm{L}$ & $0.5-0.7 \mathrm{mmol} / \mathrm{L}$ & $0.6 \mathrm{I}-0.8 \mathrm{mmol} / \mathrm{L}$ \\
\hline deficiency & $\begin{array}{l}\text { Oral replacement with } 20 \mathrm{mmol} \text { (as } \mathrm{KCl} \\
\text { or other salts) or i.v. replacement with } \\
20 \mathrm{mmol} \mathrm{KCl} \text { over } 4-8 \text { hours. Check levels } \\
\text { the next day }\end{array}$ & $\begin{array}{l}\text { Oral replacement with } 10-15 \mathrm{mmol} \mathrm{Mg} \text { - } \\
\text { chloride or } \mathrm{Mg} \text {-citrate or } \mathrm{Mg} \text {-L-aspartate } \\
\text { Oral } \mathrm{Mg} \text { should be given in divided doses } \\
\text { to minimize diarrhea (absorption process } \\
\text { is saturated at about } 5-10 \mathrm{mmol} \mathrm{Mg} \text { ) }\end{array}$ & $\begin{array}{l}\text { Oral replacement with } 0.3 \mathrm{mmol} / \mathrm{kg} / \mathrm{d} \mathrm{PO}_{4} \\
\text { (divided doses to minimize diarrhea) or i.v. } \\
\text { replacement with } 0.3 \mathrm{mmol} / \mathrm{kg} / \mathrm{d} \mathrm{PO}_{4} \text { (as } \\
\mathrm{K}_{3} \mathrm{PO}_{4} \text { or } \mathrm{Na}_{3} \mathrm{PO}_{4} \text { ) over } 8-12 \text { hours. Check } \\
\text { levels the next day }\end{array}$ \\
\hline Moderate & $2.5-3.0 \mathrm{mmol} / \mathrm{L}$ & & $0.32-0.6 \mathrm{mmol} / \mathrm{L}$ \\
\hline deficiency & $\begin{array}{l}\text { i.v. replacement with } 20-40 \mathrm{mmol} \mathrm{KCl} \text { over } \\
4-8 \text { hours. Check levels after } 8 \text { hours, if not } \\
\text { normal levels, give further } 20 \mathrm{mmol} \mathrm{KCl}\end{array}$ & & $\begin{array}{l}\text { i.v. replacement with } 0.6 \mathrm{mmol} / \mathrm{kg} / \mathrm{d} \mathrm{PO}_{4} \text { (as } \\
\mathrm{K}_{3} \mathrm{PO}_{4} \text { or } \mathrm{Na}_{3} \mathrm{PO}_{4} \text { ) over } 8-12 \text { hours. Check } \\
\text { levels after } 8-12 \text { hours and repeat infusion if } \\
\text { necessary (max. of } 50 \mathrm{mmol} \mathrm{PO}_{4} \text { in } 24 \text { hours) }\end{array}$ \\
\hline Severe & $<2.5 \mathrm{mmol} / \mathrm{L}$ & $<0.5 \mathrm{mmol} / \mathrm{L}$ & $<0.32 \mathrm{mmol} / \mathrm{L}$ \\
\hline deficiency & $\begin{array}{l}\text { i.v. replacement with } 40 \mathrm{mmol} \mathrm{KCl} \text { over } \\
4-8 \text { hours. Check levels after } 8 \text { hours, if not } \\
\text { normal levels, give further } 40 \mathrm{mmol} \mathrm{KCl}\end{array}$ & $\begin{array}{l}\text { i.v. replacement with } 20-24 \mathrm{mmol} \\
\mathrm{MgSO}_{4}(4-6 \mathrm{~g}) \text { over } 4-8 \text { hours. Reassess } \\
\text { every } 8-12 \text { hours }\end{array}$ & $\begin{array}{l}\text { Same replacement therapy as for moderate } \\
\text { deficiency }\end{array}$ \\
\hline
\end{tabular}

Abbreviation: i.v., intravenous. 


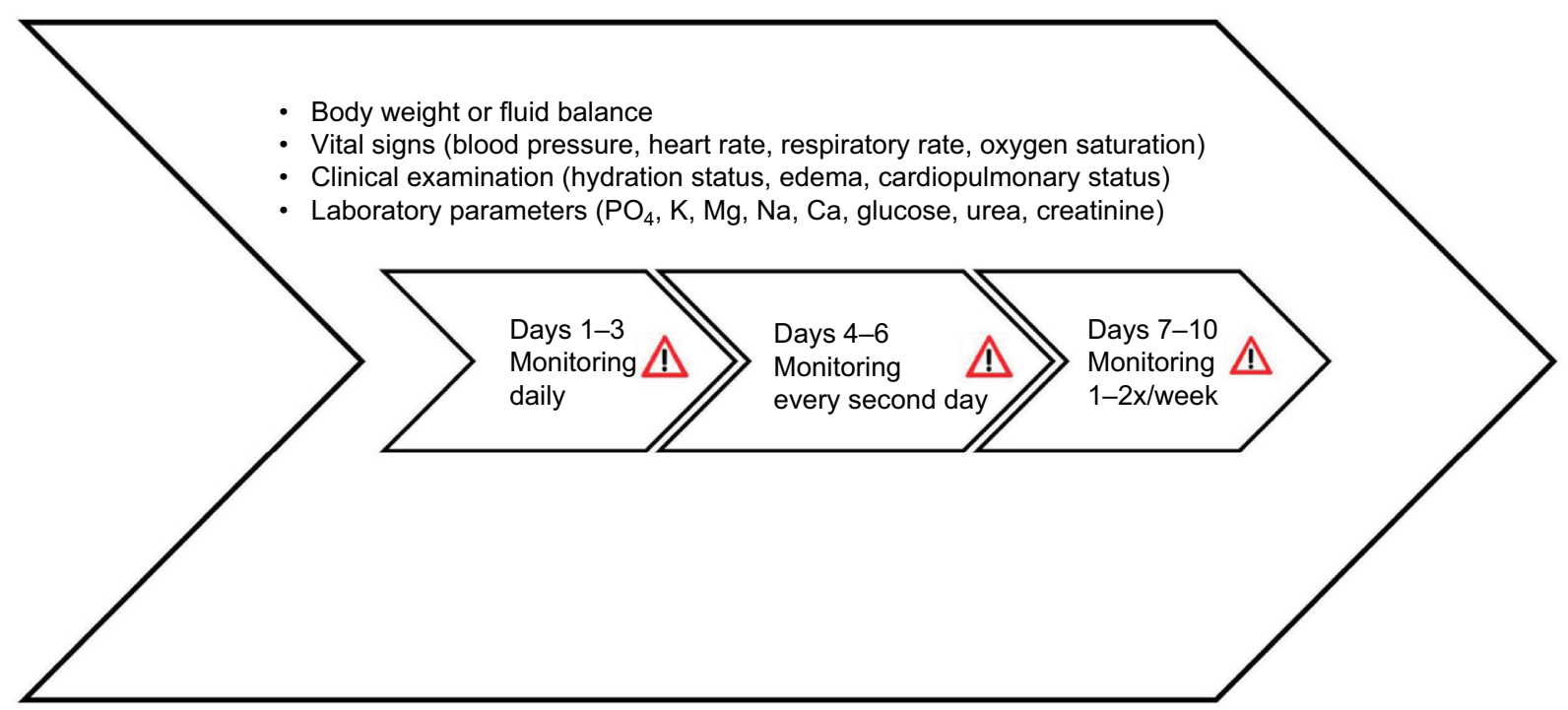

Figure 5 Monitoring of patients at risk for RFS.

Note: Used with permission of the Department of Diabetes, Endocrinology, Nutritional Medicine and Metabolism and is modified from Friedli et al. ${ }^{42}$ Abbreviation: RFS, refeeding syndrome.

\section{Monitoring}

The main issue regarding RFS is to be aware of it, to prevent it and to be able to diagnose and treat it, as it can occur and progress rapidly in the first 72 hours after the beginning of the nutritional therapy. Intensive clinical evaluation, including vital signs and hydration status, as well as blood levels, is mandatory to detect early signs of RFS, such as organ failure and fluid overload. The body weight (or fluid balance) should be checked daily, as an increase of $0.3-0.5 \mathrm{~kg} / \mathrm{d}(1.5 \mathrm{~kg} /$ week $)$ could be a sign of pathologic water retention. Laboratory measurements of phosphate, thiamine and magnesium levels may be uncommon in the elderly population, but they are essential in the monitoring of RFS (Figure 5). ${ }^{33}$

Additional ECG monitoring is recommended during the first few days in patients with a very high risk for RFS or with severe electrolyte imbalance $\left(\mathrm{K}<2.5 \mathrm{mmol} / \mathrm{L}, \mathrm{PO}_{4}<0.32\right.$ $\mathrm{mmol} / \mathrm{L}, \mathrm{Mg}<0.5 \mathrm{mmol} / \mathrm{L})$. Severe electrolyte imbalance can potentially cause severe arrhythmia and QT prolongations up to torsade de pointes, especially in older patients. ${ }^{28,29,42,46}$

\section{Conclusion}

Malnutrition is prevalent in the frail elderly population and is a main topic in geriatric medicine. Nutritional therapies are widely used to improve the nutritional status of malnourished catabolic patients. RFS may develop as a complication of nutritional rehabilitation, leading to severe complications and becoming potentially life-threatening, especially in the frail elderly, if not recognized in a timely manner and treated adequately. Thus, as the risk for malnutrition is associated with the risk for RFS, awareness of this condition among the medical staff treating elderly frail patients must increase. Broad randomized clinical studies evaluating nutritional therapy and RFS in elderly patients are needed.

\section{Acknowledgment}

The authors thank Ms Estella Hodel for the critical revision of the paper.

\section{Disclosure}

The authors report no conflicts of interest in this work.

\section{References}

1. Michelon E, Blaum C, Semba RD, Xue QL, Ricks MO, Fried LP. Vitamin and carotenoid status in older women: associations with the frailty syndrome. J Gerontol A Biol Sci Med Sci. 2006;61(6):600-607.

2. Fedarko NS. The biology of aging and frailty. Clin Geriatr Med. 2011;27(1):27-37.

3. Kelaiditi E, Cesari M, Canevelli M, et al; IANA/IAGG. Cognitive frailty: rational and definition from an (I.A.N.A./I.A.G.G.) international consensus group. J Nutr Health Aging. 2013;17(9):726-734.

4. Lang PO, Michel JP, Zekry D. Frailty syndrome: a transitional state in a dynamic process. Gerontology. 2009;55(5):539-549.

5. Schuntermann MF. The International Classification of Impairments, Disabilities and Handicaps (ICIDH) - results and problems. Int $J$ Rehabil Res. 1996;19(1):1-11.

6. Abate M, Di Iorio A, Di Renzo D, Paganelli R, Saggini R, Abate G. Frailty in the elderly: the physical dimension. Eura Medicophys. 2007;43(3):407-415.

7. Gobbens RJ, van Assen MA, Luijkx KG, Schols JM. The predictive validity of the Tilburg Frailty Indicator: disability, health care utilization, and quality of life in a population at risk. Gerontologist. 2012;52(5):619-631.

8. Shim EY, Ma SH, Hong SH, et al. Correlation between frailty level and adverse health-related outcomes of community-dwelling elderly, one year retrospective study. Korean J Fam Med. 2011;32(4):249-256. 
9. Fried LP, Tangen CM, Walston J, et al; Cardiovascular Health Study Collaborative Research Group. Frailty in older adults: evidence for a phenotype. J Gerontol A Biol Sci Med Sci. 2001;56(3):M146-M156.

10. Rodríguez-Mañas L, Féart C, Mann G, et al; FOD-CC group (Appendix 1). Searching for an operational definition of frailty: a Delphi method based consensus statement: the frailty operative definition-consensus conference project. J Gerontol A Biol Sci Med Sci. 2013;68(1):62-67.

11. Theou O, Brothers TD, Mitnitski A, Rockwood K. Operationalization of frailty using eight commonly used scales and comparison of their ability to predict all-cause mortality. J Am Geriatr Soc. 2013;61(9): $1537-1551$.

12. Gill TM, Gahbauer EA, Allore HG, Han L. Transitions between frailty states among community-living older persons. Arch Intern Med. 2006;166(4):418-423.

13. Bollwein J, Volkert D, Diekmann R, et al. Nutritional status according to the mini nutritional assessment $\left(\right.$ MNA $\left.{ }^{\circledR}\right)$ and frailty in community dwelling older persons: a close relationship. $J$ Nutr Health Aging. 2013;17(4):351-356.

14. Beasley JM, LaCroix AZ, Neuhouser ML, et al. Protein intake and incident frailty in the Women's Health Initiative observational study. $J$ Am Geriatr Soc. 2010;58(6):1063-1071.

15. Chan DC, Tsou HH, Yang RS, et al. A pilot randomized controlled trial to improve geriatric frailty. BMC Geriatr. 2012;12:58

16. Talegawkar SA, Bandinelli S, Bandeen-Roche K, et al. A higher adherence to a Mediterranean-style diet is inversely associated with the development of frailty in community-dwelling elderly men and women. J Nutr. 2012;142(12):2161-2166.

17. Tieland M, van de Rest O, Dirks ML, et al. Protein supplementation improves physical performance in frail elderly people: a randomized, double-blind, placebo-controlled trial. J Am Med Dir Assoc. 2012;13(8):720-726.

18. Deutz NE, Bauer JM, Barazzoni R, et al. Protein intake and exercise for optimal muscle function with aging: recommendations from the ESPEN Expert Group. Clin Nutr. 2014;33(6):929-936.

19. McWhirter JP, Pennington CR. Incidence and recognition of malnutrition in hospital. BMJ. 1994;308(6934):945-948.

20. Kyle UG, Pirlich M, Schuetz T, Luebke HJ, Lochs H, Pichard C. Prevalence of malnutrition in 1760 patients at hospital admission: a controlled population study of body composition. Clin Nutr. 2003;22(5):473-481.

21. Pirlich M, Schütz T, Norman K, et al. The German hospital malnutrition study. Clin Nutr. 2006;25(4):563-572.

22. Sorensen J, Kondrup J, Prokopowicz J, et al; EuroOOPS study group. EuroOOPS: an international, multicentre study to implement nutritional risk screening and evaluate clinical outcome. Clin Nutr. 2008;27(3):340-349.

23. Katona P, Katona-Apte J. The interaction between nutrition and infection. Clin Infect Dis. 2008;46(10):1582-1588.

24. Felder S, Lechtenboemer C, Bally M, et al. Association of nutritional risk and adverse medical outcomes across different medical inpatient populations. Nutrition. 2015;31(11-12):1385-1393.

25. Burger GC, Drummond DJ, Sandstead HR. Appendices to Malnutrition and Starvation in Western Netherlands, September 1944-July 1945 (part II). The Hague: The Hague General State Printing Office; 1948.

26. Keys A, Brozek J, Henschel A, et al. The Biology of Human Starvation. Minneapolis, MN: University of Minnesota Press; 1950.

27. Schnitker MA, Mattman PE, Bliss TL. A clinical study of malnutrition in Japanese prisoners of war. Ann Intern Med. 1951;35(1):69-96.

28. Crook MA, Hally V, Panteli JV. The importance of the refeeding syndrome. Nutrition. 2001;17(7-8):632-637.

29. Stanga $Z$, Brunner A, Leuenberger $M$, et al. Nutrition in clinical practice - the refeeding syndrome: illustrative cases and guidelines for prevention and treatment. Eur J Clin Nutr. 2008;62(6):687-694.

30. Solomon SM, Kirby DF. The refeeding syndrome: a review. JPEN J Parenter Enteral Nutr. 1990;14(1):90-97.

31. Preiser JC, van Zanten AR, Berger MM, et al. Metabolic and nutritional support of critically ill patients: consensus and controversies. Crit Care. 2015;19:35.
32. Felder S, Braun N, Stanga Z, et al. Unraveling the link between malnutrition and adverse clinical outcomes: association of acute and chronic malnutrition measures with blood biomarkers from different pathophysiological states. Ann Nutr Metab. 2016;68(3):164-172.

33. Courtaz M, Gay N. Refeeding syndrome: unrecognized in geriatric medicine. J Am Med Dir Assoc. 2014;15(11):848-849.

34. Bally MR, Blaser Yildirim PZ, Bounoure L, et al. Nutritional support and outcomes in malnourished medical inpatients: a systematic review and meta-analysis. JAMA Intern Med. 2016;176(1):43-53.

35. Pourhassan M, Cuvelier I, Gehrke I, et al. Risk factors of refeeding syndrome in malnourished older hospitalized patients. Clin Nutr. Epub 2017 Jun 10

36. Boateng AA, Sriram K, Meguid MM, Crook M. Refeeding syndrome: treatment considerations based on collective analysis of literature case reports. Nutrition. 2010;26(2):156-167.

37. McCray S, Walker S, Parrish CR. Much ado about refeeding. Pract Gastroenterol. 2005;29:26-44.

38. Mehanna HM, Moledina J, Travis J. Refeeding syndrome: what it is, and how to prevent and treat it. BMJ. 2008;336(7659):1495-1498.

39. Mehler PS, Winkelman AB, Andersen DM, Gaudiani JL. Nutritional rehabilitation: practical guidelines for refeeding the anorectic patient. J Nutr Metab. 2010;2010:625782.

40. Brooks MJ, Melnik G. The refeeding syndrome: an approach to understanding its complications and preventing its occurrence. Pharmacotherapy. 1995;15(6):713-726.

41. Ornstein RM, Golden NH, Jacobson MS, Shenker IR. Hypophosphatemia during nutritional rehabilitation in anorexia nervosa: implications for refeeding and monitoring. J Adolesc Health. 2003;32(1):83-88.

42. Friedli N, Stanga Z, Culkin A, et al. Management and prevention of refeeding syndrome in medical inpatients: an evidence-based and consensus-supported algorithm. Nutrition. 2018;47:13-20.

43. Friedli N, Stanga Z, Sobotka L, et al. Revisiting the refeeding syndrome: results of a systematic review. Nutrition. 2017;35:151-160.

44. Schütz P, Bally M, Stanga Z, Keller U. Loss of appetite in acutely ill medical inpatients: physiological response or therapeutic target? Swiss Med Wkly. 2014;144:w13957.

45. Schuetz P. "Eat your lunch!" - controversies in the nutrition of the acutely, non-critically ill medical inpatient. Swiss Med Wkly. 2015;145:w14132.

46. National Institute for Health and Clinical Excellence (NICE). Oral nutrition support, enteral tube feeding and parenteral nutrition. Clinical Guideline. Report No. 32. London: National Health Service; 2006. Available from: https://www.nice.org.uk/guidance/cg32/resources/nutrition-supportfor-adults-oral-nutrition-support-enteral-tube-feeding-and-parenteralnutrition-pdf-975383198917. Accessed September 11, 2017.

47. Zeki S, Culkin A, Gabe SM, Nightingale JM. Refeeding hypophosphataemia is more common in enteral than parenteral feeding in adult in patients. Clin Nutr. 2011;30(3):365-368.

48. Goyale A. Predicting refeeding syndrome: insulin growth factor 1 (IGF-1) as a diagnostic biochemical marker for clinical practice. Clin Nutr. 2013;32:S16.

49. Terlevich A, Hearing SD, Woltersdorf WW, et al. Refeeding syndrome: effective and safe treatment with phosphates polyfusor. Aliment Pharmacol Ther. 2003;17(10):1325-1329.

50. Rio A, Whelan K, Goff L, Reidlinger DP, Smeeton N. Occurrence of refeeding syndrome in adults started on artificial nutrition support: prospective cohort study. BMJ Open. 2013;3(1):e002173.

51. Gaudiani JL, Sabel AL, Mehler PS. Low prealbumin is a significant predictor of medical complications in severe anorexia nervosa. Int $J$ Eat Disord. 2014;47(2):148-156.

52. Brown C, Mehler PS. Anorexia nervosa complicated by diabetes mellitus: the case for permissive hyperglycemia. Int J Eat Disord. 2014;47(6):671-674.

53. Vignaud M, Constantin JM, Ruivard M, et al; AZUREA group (AnorexieRea Study Group). Refeeding syndrome influences outcome of anorexia nervosa patients in intensive care unit: an observational study. Crit Care. 2010;14(5):R172. 
54. Fan CG, Ren JA, Wang XB, Li JS. Refeeding syndrome in patients with gastrointestinal fistula. Nutrition. 2004;20(4):346-350.

55. Hearing SD. Refeeding syndrome. BMJ. 2004;328(7445):908-909.

56. Kraaijenbrink BV, Lambers WM, Mathus-Vliegen EM, Siegert CE. Incidence of refeeding syndrome in internal medicine patients. Neth $J$ Med. 2016;74(3):116-121.

57. Hernàndez-Aranda JC, Gallo-Chico $\mathrm{B}$, Luna-Cruz ML, et al. Desnutrición y nutrición parenteral total: estudio de una cohorte para determinar la incidencia del síndrome de realimentación [Malnutrition and total parenteral nutrition: a cohort study to determine the incidence of refeeding syndrome]. Rev Gastroenterol Mex. 1997;62(4):260-265. Spanish [with English abstract].

58. Kagansky N, Levy S, Koren-Morag N, Berger D, Knobler H. Hypophosphataemia in old patients is associated with the refeeding syndrome and reduces survival. $J$ Intern Med. 2005;257(5):461-468.

59. Kondrup J, Rasmussen HH, Hamberg O, Stanga Z; Ad Hoc ESPEN Working Group. Nutritional risk screening (NRS 2002): a new method based on an analysis of controlled clinical trials. Clin Nutr. 2003;22(3):321-336.

60. Stratton RJ, Hackston A, Longmore D, et al. Malnutrition in hospital outpatients and inpatients: prevalence, concurrent validity and ease of use of the "malnutrition universal screening tool" ("MUST") for adults. Br J Nutr. 2004;92(5):799-808.

61. Guigoz Y, Vellas B, Garry PJ. Assessing the nutritional status of the elderly: the Mini Nutritional Assessment as part of the geriatric evaluation. Nutr Rev. 1996;54(1 Pt 2):S59-S65.

62. Marvin VA, Brown D, Portlock J, Livingstone C. Factors contributing to the development of hypophosphataemia when refeeding using parenteral nutrition. Pharm World Sci. 2008;30(4):329-335.

63. Marik PE, Bedigian MK. Refeeding hypophosphatemia in critically ill patients in an intensive care unit. A prospective study. Arch Surg. 1996;131(10):1043-1047.

64. Tsiompanou E, Lucas C, Stroud M. Overfeeding and overhydration in elderly medical patients: lessons from the Liverpool Care Pathway. Clin Med (Lond). 2013;13(3):248-251.

65. Lobo DN, Lewington AJP, Allison SP. Basic Concepts of Fluid and Electrolyte Therapy. Melsungen: ${ }^{\circ}$ Bibliomed, Medizinische Verlagsgesellschaft mbH; 2013.
66. DeFronzo RA. The effect of insulin on renal sodium metabolism. A review with clinical implications. Diabetologia. 1981;21(3): $165-171$.

67. Care NCCfA. Nutrition Support in Adults: Oral Nutrition Support, Enteral Tube Feeding and Parenteral Nutrition. London: National Collaborating Center for Acute Care; 2006.

68. Winter TA, O'Keefe SJ, Callanan M, Marks T. The effect of severe undernutrition and subsequent refeeding on whole-body metabolism and protein synthesis in human subjects. JPEN J Parenter Enteral Nutr. 2005;29(4):221-228.

69. Henderson S, Boyce F, Sumukadas D, Witham MD. Changes in serum magnesium and phosphate in older hospitalised patients - correlation with muscle strength and risk factors for refeeding syndrome. J Nutr Health Aging. 2010;14(10):872-876.

70. Doig GS, Simpson F, Heighes PT, et al; Refeeding Syndrome Trial Investigators Group. Restricted versus continued standard caloric intake during the management of refeeding syndrome in critically ill adults: a randomised, parallel-group, multicentre, single-blind controlled trial. Lancet Respir Med. 2015;3(12):943-952.

71. Knochel JP. Hypophosphatemia. Clin Nephrol. 1977;7(4):131-137.

72. Huang CL, Kuo E. Mechanism of hypokalemia in magnesium deficiency. J Am Soc Nephrol. 2007;18(10):2649-2652.

73. Fierz YC, Kenmeni R, Gonthier A, Lier F, Pralong F, Coti Bertrand P. Severe and prolonged hypophosphatemia after intravenous iron administration in a malnourished patient. Eur J Clin Nutr. 2014;68(4): 531-533.

74. Brannan PG, Vergne-Marini P, Pak CY, Hull AR, Fordtran JS. Magnesium absorption in the human small intestine. Results in normal subjects, patients with chronic renal disease, and patients with absorptive hypercalciuria. J Clin Invest. 1976;57(6):1412-1418.

75. Gennari FJ. Hypokalemia. N Engl J Med. 1998;339(7):451-458.

76. Marinella MA. Refeeding syndrome in cancer patients. Int J Clin Pract. 2008;62(3):460-465.

77. Thatte L, Oster JR, Singer I, Bourgoignie JJ, Fishman LM, Roos BA. Review of the literature: severe hyperphosphatemia. Am J Med Sci. 1995;310(4):167-174.

78. Weisinger JR, Bellorín-Font E. Magnesium and phosphorus. Lancet. 1998;352(9125):391-396.
Clinical and Experimental Gastroenterology

\section{Publish your work in this journal}

Clinical and Experimental Gastroenterology is an international, peerreviewed, open access, online journal publishing original research, reports, editorials, reviews and commentaries on all aspects of gastroenterology in the clinic and laboratory. This journal is included on PubMed. The manuscript management system is completely online

\section{Dovepress}

and includes a very quick and fair peer-review system, which is all easy to use. Visit http://www.dovepress.com/testimonials.php to read real quotes from published authors. 